TUNJUK AJAR: JURNAL PENELITIAN ILMU PENDIDIKAN

Volume 4, Nomor 1, Februari 2021

P-ISSN: 2615-062X

E-ISSN: 2622-3554

http://dx.doi.org/10.31258/ita.v4i1.16-25

\title{
HUBUNGAN MINAT BELAJAR SISWA TERHADAP HASIL BELAJAR FISIKA DI SMA N 3 MUARO JAMBI
}

\section{Fauziah Yolviansyah ${ }^{1 *}$, Suryanti ${ }^{1}$, Endah Febri Setiya Rini ${ }^{1}$, Sri Wahyuni ${ }^{1}$, Maria Marisa Matondang ${ }^{1}$ \\ ${ }^{1}$ Program Studi Pendidikan Fisika, Fakultas Keguruan Dan IImu Pendidikan, Universitas Jambi, Jambi, Indonesia \\ *fauziahyolviansyah1@gmail.com}

\section{ABSTRACT}

This study ams to determine the relationship between interst in learning physics and student leraning outcomes. This research uses a quantutative research type, with the research instrument using a questionnaire. . The focus of this research is on 4 dimensions, namely the adoption of a scientific attitude, the pleasure of learning physics, and an interest in learning physics. The sample of this research was students of class XII MIA with a total of 60 students. This research was conducted at SMA N 3 MUARO JAMBI. Then, the data were analyzed using the SPSS 24 program to determine whether the data was normal, and using the Kolmogorov-Smirnov correlation test to see whether each variable had a relationship with one another. Based on research and test results from the Kolmogorov-Smirnov correlation test, a significance value of 0,000 was obtained. This means that the significance value of $0.000<0.05$, which indicates that the relationship between the two variables is very related or highly correlated.

Keywords: achievements; interests; physics.

\section{PENDAHULUAN}

Seperti yang kita ketahui bahwa pendidikan merupakan bagian yang sangat penting dalam proses pembangunan suatu bangsa dan negara. Pendidikan harus didapatkan oleh setiap lapisan masyarakat agar meningkatkan kualitas sumber daya manusia yang baik seperti yang dikatakan oleh Sujana (2019, p.30). Akan tetapi, pendidikan di Indonesia masih tergolong rendah. Hal ini disebabkan oleh beberapa faktor seperti masih banyak siswa yang sering tidak masuk dalam jam pelajaran, siswa sering mencontek, minat siswa yang rendah di bebarapa mata pelajaran khususnya di fisika dan cara guru mengajar yang belum membuat siswa 
tertarik. Seperti yang dikatakan oleh Astalini et al (2018, p.59), bahwa Minat belajar fisika siswa yang rendah menyebabkan siswa malas mengerjakan tugas, kurang suka membaca buku yang berkenaan dengan fisika, dan merasa senang bila tidak belajar fisika bila guru tidak hadir.

Padahal minat sangatlah berpengaruh dalam proses pembelajaran, karena dengan adanya minat efektivitas siswa dalam pembelajaran akan meningkat yang tentunya akan diikuti oleh meningkatnya hasil belajar siswa. Siswa akan lebih aktif dalam proses pembelajaran baik dalam menanggapi, berkomunikasi, dan mencari informasi secara mandiri, karena siswa akan berusaha lebih keras untuk belajar dibandingkan ketika siswa tidak memiliki minat dalam pembelajarn tersebut. Selain itu, dengan adanya minat siswa akan lebih merasa gembira ketika melaksanakan pembelajaran. Hal ini didukung oleh Putri et al (2017, p.68), dalam penelitiannya yaitu siswa yang menaruh minat besar terhadap pelajaran akan memusatkan perhatian lebih banyak dan berusaha untuk memahami materi dan memperhatikan guru saat menjelaskan, siswa akan lebih aktif dalam menumukan pengetahuan, informasi dan aktif dalam berpendapat.

\section{Minat belajar}

Minat pada dasarnya merupakan pendorong kuat bagi siswa untuk terlibat secara aktif dalam proses pembalajaran seperti yang dikatakan oleh Ricardo dan Meilani (2017, p.190), minat belajar merupakan pendorong siswa dalam belajar yang di dasari atas ketertarikan atau raasa senang dan keinginan siswa untuk belajar, minat juga merupakan aspek pembangun motivasi, fenomena yang terbentuk akibat interaksi sosial, dan keterlibatan siswa dalam kegiatan belajar. Selanjutnya, Sirait ( 2016, p.37) mengatakan bahwa minat adalah kecenderungan jiwa terhadap sesuatu yang terdiri dari perasaan senang, memperhatikan, kesungguhan, adanya motif dan tujuan dalam mencapai suatu tujuan. Hal ini dipertegas oleh Laras dan Rifai $(2019$, p.125), minat adalah keinginan atau dorongan yang dimiliki individu yang bertujuan untuk mencapai tujuan yang akan di capai secara maksimal, dimana minat yang baik akan sangat mempengaruhi hasil belajar di dalam proses pembelajaran. Dari beberapa pendapat diatas, dapat 
kita simpulkan bahwa minat adalah keinginan yang mendorong sorang individu untuk mencapai tujuan yang diinginkan secara maksimal atas dasar rasa senang, ketertarikan dan berusaha lebih keras untuk mencapai hasil tersebut.

\section{Indikator minat belajar}

Menurut Syahputra (2020, p.19), indikator minat ada empat yaitu: (1) Perasaan senang, siswa yang memiliki perasaan senag atau suka terhadap suatu mata pelajaran akan terus mempelajari ilmu yang disenanginya tersebut sehingga siswa akan memiliki pemahaman yang mendalam tentang ilmu tersebut. (2) Ketertarikan siswa, ketertarikan akan mendorong siswa cenderung untuk merasa tertarik pada orang, benda, kegiatan atau bisa berubah pengalaman afektif yang dirangsang oleh kegiatan itu sendiri. (3) Perhatian siswa, perhatian merupakan konsentrasi atau aktifitas jiwa terhadap pengamatan dan pengertian. (4) Keterlibatan siswa, keterlibatan ini akan mengakibatkan orang tersebut merasa senang dan tertarik untuk mengerjakan kegiatan dari objek tersebut.

Menurut Friantini dan Winata (2019, p.7), indikator minat belajar yaitu adanya perasaan senang terhadap pembelajaran, adanya pemusatan perhatian dan pikiran pembelajaran, adanya kemauan untuk belajar, adanya kemauan dalam diri untuk aktif dalam pembelajaran, adanya upaya yang dilakukan untuk merealisasikan keinginan untuk belajar. Menurut Hidayat (2013) dalam Pratiwi (2015, p.89), beberapa indikator yang menentukan minat sesorang terhadap sesuatu antara lain: (1) Keinginan, (2) Perasaan senang, (3) Perhatian, (4) Perasaan tertarik, (5) Giat belajar, (6) Mengerjakan tugas, (7) Menaati peraturan. Dari beberapa pendapat ahli diatas dapat disimpulkan bahwa indikator yang menandakan siswa memiliki minat belajar adalah adanya perasaan positif terhadap pembelajaran, adanya kenyamanan saat proses pembelajaran, adanya keinginan untuk menjadi lebih aktif dan keingan untuk mengerjakan tugas, adanya kemampuan untuk membuat keputusan yang berkaitan dengan pembelajaran. 


\section{Upaya peningkatan minat belajar}

Menurut Eriyanto (2017, p.369), upaya meningkatkan minat belajar siswa tak terlepas dari peran guru sebagai pengelola kelas guru hendaknya dapat mengelola kelas dengan baik sehingga dapat membangitkan minat belajar siswa. Menurut Marleni (2016, pp.151-152), minat belajar di pengaruhi oleh faktor ekternal dan internal. Dimana faktor internal tersebut antara lain perhatian siswa yang muncul karena rasa ingin tahu, sikap siswa dan bakat siswa. Lalu faktor eksternal yaitu faktor skolah dan factor keluarga. Menurut Kicardo dan Meilani ( 2017, p.191), upaya dalam meningkatkan minat belajar sangatlah variatif. Salah satunya adalah melalui peran guru, guru bias meningkatkan minat siswa dengan cara menciptakan lingkungan belajar kondusif \& kooperatif, melibatkan siswa dalam setiap pembelajaran melalui komunikasi positif, dan melakukan pendekatan pengetahuan dan implementasi materi pada kehidupan sehari hari siswa. Dari beberapa pendapat diatas dapat disimpulkan bahwa upaya meningkatkan minat belajar di pengaruhi oleh beberapa faktor seperti peran orang tua, lingkungan, rasa keingin tahuan siswa dan komunikasi yang positif.

\section{Hasil belajar}

Menurut Humaira at al ( 2015, p.64), hasil belajr merupakan perubahan yaitu ketika sesorang melakukan aktifitas belajar dan memperoleh perubahan dalam dirinya dengan memperoleh pengalaman baru, yang dapat dilihat dari prilakunya, baik prilaku dalam membentuk pengetahuan, ketrampilan berfikir atau pun keterampilan motoric. Menurut Arianto ( 2016, p.135), hasil belajar adalah perubahan berupa kecakapan fisik, mental, intekektual yang berproses dari kegiatan belajar baik dijenjang pendidikan formal seperti sekolah ataupun non formal seperti dilingkungan keluarga atau masyarakat. Menurut Wahyuningsih (2020, p.65), hasil belajar adalah kemampuan yang dimiliki siswa setelah mereka menerima pengalaman belajar dalam proses pembelajaran. Yang mana, perubahan ini dapat dilihat dari prilaku dan kemampuan siswa setelah belajar yang mana wujudnya berupa kemampuan kognitif, afektif, dan psikomotor yang disebabkan oleh pengalaman dalam proses pembelajaran. Dari pendapat ahli 
tersebut, dapat disimpulkan bahwa hasil belajar merupakan perubahan yang diperoleh oleh siswa baik dlam kemampuan kognitif afektif dan psikomotor yang diperoleh melalui pengalaman pengalaman baru.

Berdasarkan penelitian yang akan dilakukan,tujuan dari penelitian ini adalah

(1) Untuk mengetahui pengaruh minat terhadap hasil belajar,

(2) Keterkaitan antara minat dan hasil belajar,

(3) Mengetahui kendala apa saja yang menyebabkan kurangnya minat belajar pada siswa.

Melalui temuan atau hasil penelitian ini, diharapkan dapat membantu guru fisika dalam meningkatkan hasil belajar siswa melalui peningkatan minat belajar siswa.

\section{METODE PENELITIAN}

Jenis Penelitian

Penelitian ini menggunakan Jenis penelitian kuantitatif. Menurut Mulyadi (2011:132), Penelitian kuantitatif adalah penelitian yang menguji hubungan antara variabel yang dihipotesiskan, apakah suatu variabel disebabkan atau dipengaruhi atau tidak oleh varibael lainnya, data penelitian ini hanya berupa angka. Subjek penelitian ini adalah siswa SMA N 3 MUARO JAMBI kelas XII MIA 1,3, dan 4 yang berjumlah 60 siswa.

\section{Instrumen Penelitian}

Instrumen penelitian menggunakan angket yang diadopsi dari penelitian Yosefin Sulistyawantic Gulo (2016). Ada 30 item pertanyaan yang valid, pada instrumen ini menggunakan skala likert. Skala tersebut terdiri dari 5 point yaitu sangat setuju (5), setuju (4), netral (3), tidak setuju (2), dan sangat tidak setuju (1). Setiap pertanyaan merupakan perwakilan dari setiap indikator minat yang diteliti. Fokus penelitian ini terdapat 4 dimensi yaitu adopsi dari sikap ilmiah, kesenangan belajar fisika, dan ketertarikan dalam belajar fisika. 


\section{Teknik Analisis Data}

Untuk menggambarkan data berupa minat siswa, maka statistik yang digunakan adalah statistik deskriptif. Data dianalisis menggunakan Program SPSS 24 untuk memperoleh apakah data tersebut normal, serta menggunakan uji korelasi untuk melihat apakah setiap variable memiliki hubungan satu sama lainnya.

\section{HASIL DAN PEMBAHASAN}

\section{Hasil Penelitian}

Sebelum melakukan penelitian dilakukan penyusunan angket dimana pertanyaan dalam angket mengacu pada indikator minat belajar, diantaranya yaitu perasaan senang, ketertarikan, partisipasi serta ketertarikan. setalah diperoleh hasil data, selanjutnya dilakukan uji normalitas dan korelasi. Hasil pengolahan data minat siswa terhadap hasil belajar fisika di SMA N 3 MUARO JAMBI KELAS XII MIA 1, 3, 4 dapat dideskripsikan oleh tabel berikut :

Table 1. Uji Normalitas Kelas XII MIA 1

\begin{tabular}{|l|l|l|l|l|l|l|}
\hline & \multicolumn{3}{|l|}{ Kolmogorov- $^{2}$ Smirnov $^{\mathrm{a}}$} & \multicolumn{3}{l|}{ Shapiro-Wilk } \\
\cline { 2 - 7 } & Statistic & df & Sig. & Statistic & df & Sig. \\
\hline Pg xii mia 1 &, 141 & 60 &, 005 &, 964 & 60 &, 075 \\
Minat xii mia 1 &, 104 & 60 &, 172 &, 979 & 60 &, 399 \\
\hline
\end{tabular}

Tabel 2. Uji Normalitas Kelas XII MIA 3

\begin{tabular}{|l|l|l|l|l|l|l|}
\hline & \multicolumn{3}{|l|}{ Kolmogorov-Smirnov $^{\text {a }}$} & \multicolumn{3}{l|}{ Shapiro-Wilk } \\
\cline { 2 - 7 } & Statistic & df & Sig. & Statistic & df & Sig. \\
\hline xii mia 3 &, 164 & 20 &, 163 &, 952 & 20 &, 391 \\
xii mia 3 &, 179 & 20 &, 092 &, 875 & 20 &, 014 \\
\hline
\end{tabular}


Tabel 3. Uji Normalitas Kelas XII MIA 4

\begin{tabular}{|l|l|l|l|l|l|l|}
\hline \multirow{2}{*}{} & \multicolumn{3}{|l|}{ Kolmogorov-Smirnov $^{\text {a }}$} & \multicolumn{3}{|l|}{ Shapiro-Wilk } \\
\cline { 2 - 7 } & Statistic & Df & Sig, & Statistic & Df & Sig, \\
\hline xii mia 4 &, 129 & 20 &, 200 & .932 & 20 &, 167 \\
xii mia 4 &, 135 & 20 &, $200^{*}$ & .941 & 20 &, 255 \\
\hline
\end{tabular}

Setelah peneliti melakukan uji normalitas, kemudian dilakukan lah uji korelasi supaya mengetahui ada atau tidaknya hubungan antara kedua variabel tersebut. Dan didapatkan lah hasil sebagai berikut:

Tabel 4. Uji korelasi kelas XII MIA 1, 3, dan 4

\begin{tabular}{|c|c|c|c|c|}
\hline & & & $\begin{array}{l}\text { XII MIA 1, } \\
3,4\end{array}$ & $\begin{array}{l}\text { XII MIA 1, } \\
3,4\end{array}$ \\
\hline \multirow[t]{2}{*}{$\begin{array}{l}\text { Kendall's } \\
\text { tau_b }\end{array}$} & $\begin{array}{l}\text { XII MIA } \\
1,3,4\end{array}$ & $\begin{array}{l}\text { Correlation } \\
\text { Coefficient } \\
\text { Sig. (2-tailed) } \\
\mathrm{N}\end{array}$ & $\begin{array}{l}1.000 \\
60 \\
\end{array}$ & $\begin{array}{l}.965^{* *} \\
.000 \\
60 \\
\end{array}$ \\
\hline & $\begin{array}{l}\text { XII MIA } \\
1,3,4\end{array}$ & $\begin{array}{l}\text { Correlation } \\
\text { Coefficient } \\
\text { Sig. (2-tailed) } \\
\text { N }\end{array}$ & $\begin{array}{l}.965^{*} \\
.000 \\
60\end{array}$ & $\begin{array}{l}1.000 \\
60\end{array}$ \\
\hline
\end{tabular}

\section{Pembahasan}

Minat pada dasarnya adalah kecenderungan penerimaan suatu hubungan antar diri sendiri dengan suatu kegiatan di luar diri. Semakin kuat atau dekat hubungan tersebut maka semakin besar minatnya, dimana minat ini dapat ditunjukkan melalui partisipasi sesorang dalam suatu aktifitasnya. Dalam pembelajaran, minat juga memiliki peran yang sangat penting untuk memperoleh hasil pembelajaran yang maksimal. Karena, jika siswa memiliki minat yang tinggi terhadap suatu pelajaran akan senantiasa memfokuskan diri dalam pelajaran tersebut sehingga hasil yang di dapatkan dari siswa tersebut akan maksimal. 
Minat memiliki pengaruh yang besar terhadap hasil pembelajaran, karena dengan adanya minat belajar maka siswa akan merasa lebih tertarik pada pembelajaran dan ditunjukkan dengan adanya keaktifan, partisipasi serta keantusiasan dalam proses pembelajaran. Menurut Sirait (2016), dalam penelitiannya bahwa besar pengaruh minat terhadap pembelajaran, merupakan faktor utama yang menetukan derajat keaktifan siswa, bila bahan pelajaran yang di pelajari tidak sesuai dengan minat, siswa tidak akan belajar dengan baik sebab tidak ada daya tarik di dalam pembelajaran. Minat didapat dari suasana pembelajaran yang akan memberikan motivasi dan kebebasan, meganalisis pengalaman belajar Yuliana, Putra, \& Antosa, 2020; Lestari, Syahrilfuddin, Putra, \& Hermita, 2019). Sehingga siswa harus dirangsang agar memiliki minat pembelajaran. Dalam hal ini, guru memiliki peran penting, seperti pada data angket siswa mengatakan bahwa tertarikan mereka dalam pembelajaran juga tergantung pada bagaimana cara guru mengajar, lingkukngan kelas, teman teman kelas dan lain sebaginya.

Dalam data observasi yang telah dilakukan bahwa siswa SMA N 3 Muara Jambi memiliki minat belajar yang cukup baik, hal ini dilihat dari hubungan antara minat dengan hasil pembelajaran yang di dapat siswa. Data diuji menggunakan uji normalitas dan uji korelasi. Dari uji normalitas pada ketiga tabel diatas di dapatkan bahwa probabilitas signifikansinya adalah $>0,05$. Menurut As'ari (2018), syarat pedoman dalam pengambilan keputusan dengan uji normalitas KolmogorovSmirnov dalam SPSS, yaitu:

1. Nilai signifikansi $<0,05$ maka data tidak normal.

2. Nilai signifikansi $>0,05$ maka data dikatakan normal

Sehingga, ketiga data pada tabel 1 , tabel 2 , dan tabel 3 dapat dikatakan berdistribusi normal.

Kemudian, setelah dilakukan uji normalitas maka dilakukan uji korelasi. Pada tabel 4 diatas diperoleh nilai signifikansi adalah 0,000. Angka nilai signifikansi $0,000<0,05$ dengan demikian maka $\mathrm{H}_{0}$ ditolak dan $\mathrm{H}_{1}$ diterima. Hal ini menunjukkan bahwa terdapat hubungan antara kedua variabel tersebut. Selain itu, 
angka korelasi antara minat belajar siswa dan hasil belajar siswa didapatkan sebesar 0,965 yang berarti hubungan korelasi antar kedua variabel adalah sangat kuat. Kemudian, jika ditinjau pada tanda ** yang berarti terdapat hubungan korelasi yang positif. Dari sini, dapat disimpulkan bahwa terdapat hubungan korelasi yang kuat dan positif dari minat belajar fisika terhadap hasil belajar siswa. Hal ini, sejalan dengan penelitian Restasari et al (2015) dan Charli et al (2019) bahwa minat belajar fisika memiliki hubungan yang signifikan terhadap hasil belajar siswa.

\section{SIMPULAN}

Berdasarkan data yang diperoleh dari hasil analisis data serta pengujian menggunakan uji normalitas dan korelasi dapat ditarik kesimpulan yaitu minat belajar siswa berkorelasi kuat dan positif terhadap hasil belajar siswa di SMA N 3 MUARO JAMBI kelas XII MIA 1, 3, dan 4.

\section{DAFTAR PUSTAKA}

Abbas, A. (2017). Faktor-faktor Kesulitan Belajar Fisika pada Peserta Didik Kelas IPA di SMA Negri 1 Bontonompo (Doctoral dissertation, Universitas Islam Negeri Alauddin Makassar).

Ariyanto, M. (2016). Peningkatan Hasil Belajar IPA Materi Kenampakan Rupa Bumi Menggunakan Model Scramble. Profesi Pendidikan Dasar, 3(2), 134140.

As'ari, Ruli. (2018). Pengetahuan dan Sikap Masyarakat Dalam Melestarikan Lingkungan Hubungannya dengan Perilaku Menjaga Kelestarian Kawasan Bukit Sepuluh Ribu di Kota Tasikmalaya. Jurnal GeoEco. 4(1).

Carli, L., Ariani, T., \& Asmara, L. (2019). Hubungan Minat Belajar Terhdap Prestasi Belajar Fisika. SPEJ. 2(2).

Laras, S. A., \& Rifai, A. (2019). Pengaruh Minat dan Motivasi Belajar terhadap Hasil Belajar Peserta Didik di BBPLK Semarang. Jurnal Eksistensi Pendidikan Luar Sekolah (E-Plus), 4(2). 
Lestari, S., Syahrilfuddin, S., Putra, Z. H., \& Hermita, N. (2019). The Effect of Realistic Mathematic Approach on Students' Learning Motivation, Journal of Teaching and Learning in Elementary Education, 3(2), 145-156.

Nurhasanah, S., \& Sobandi, A. (2016). Minat belajar sebagai determinan hasil belajar siswa. Jurnal Pendidikan Manajemen Perkantoran (JPManper), 1(1), 128-135.

Pratiwi, N. K. (2017). Pengaruh Tingkat Pendidikan, Perhatian Orang Tua, Dan Minat Belajar Siswa Terhadap Prestasi Belajar Bahasa Indonesia Siswa Smk Kesehatan Di Kota Tangerang. Pujangga, 1(2), 31.

Putri, D. T. N., \& Isnani, G. (2015). Pengaruh minat dan motivasi terhadap hasil belajar pada mata pelajaran pengantar administrasi perkantoran. JPBM (Jurnal Pendidikan Bisnis dan Manajemen), 1(2), 118-124.

Restasari., Arini, W., Ariani, Tri. (2015). Hubungan Minat Belajar Terhadap Hasil Belajar Fisika Kelas Xi Ma Mazro'illah Lubuk Linggau Tahun Ajaran 2015/2016. JURNAL ILMIAH.

Ricardo, R., \& Meilani, R. I. (2017). Impak minat dan motivasi belajar terhadap hasil belajar siswa. Jurnal Pendidikan Manajemen Perkantoran (JPManper), 2(2), 188-201.

Sirait, E. D. (2016). Pengaruh minat belajar terhadap prestasi Belajar Matematika. Formatif: Jurnal IImiah Pendidikan MIPA, 6(1).

Situmorang, P., \& Nurrahman, A. (2019). Analisis Perilaku Jujur Siswa dalam Pembelajaran IPA Terpadu Materi Kalor dan Perpindahannya di SMP Negeri 6 Kota Jambi. Jurnal Nalar Pendidikan, 7(1), 71-79.

Sujana, I. W. C. (2019). Fungsi Dan Tujuan Pendidikan Indonesia. Adi Widya: Jurnal Pendidikan Dasar, 4(1), 29-39.

Yuliana, Y., Putra, M. J. A., \& Antosa, Z. (2020). Faktor-Faktir yang Mempengaruhi Motivasi Siswa Sekolah Dasar dalam Mengikuti Aktivitas Pramuka Penggalang. Tunjuk Ajar: Jurnal Penelitian Ilmu Pendidikan, 3(2), 210-226. 